\title{
Trakea Yerleşimli Adenoid Kistik Karsinom: Olgu Sunumu
}

\section{Tracheal Adenoid Cystic Carcinoma: Case Report}

\author{
Deniz KÜTRI' ${ }^{1}$, Alaattin ÖZEN ${ }^{1}$, Suzan ŞAYLISOY ${ }^{2}$ \\ ${ }^{1}$ Eskişehir Osmangazi Üniversitesi Tıp Fakültesi Radyasyon Onkolojisi Anabilim Dalı, Eskişehir \\ ${ }^{2}$ Eskişehir Osmangazi Üniversitesi Tıp Fakültesi Radyoloji Anabilim Dalı, Eskişehir
}

\begin{abstract}
$\ddot{\mathbf{O} z}$
Adenoid Kistik Karsinom, 100000’de 0.1-0.26 görülme insidansı ile oldukça nadir görülen bir hastalıktır. Trakeanın ikinci en sık görülen primer malignitesi olmakla birlikte cerrahi rezeksiyon esas tedavi yöntemidir. Ancak cerrahi olamayacak hastalarda ya da cerrahi sonrası mikroskobik/makroskobik rezidü hastalık varlığında radyoterapi önerilmektedir. Nadir görülen bir tümör olması ve cerrahi sınır pozitifliği nedenleri ile küratif radyoterapi uyguladığımız 38 yaşında kadın olguyu sunmayı amaçladık.
\end{abstract}

Anahtar Kelimeler: Adenoid Kistik Karsinom, Radyoterapi, Trakea

\section{Giriş}

Adenoid kistik karsinom en sık majör ve minör tükürük bezlerinden köken alan akciğer, meme ve serviks başta olmak üzere diğer organlarda da görülebilen nadir bir kanserdir. Trakeal yerleşimli adenoid kistik karsinom oldukça nadir görülen, yavaş büyüme eğiliminde olan düşük malign potansiyele sahip bir tümör olup primer tedavisi cerrahi rezeksiyondur (1-3). Bu yazımızda cerrahi sınır pozitifliği nedeni ile küratif radyoterapi uyguladığımız nadir görülen trakeal yerleşimli adenoid kistik karsinom olgusu sunmayı amaçladık.

\section{Olgu}

Trakeal kitle eksizyonu + tiroid sağ lob rezeksiyonu uygulanan ve patoloji sonucu adenoid kistik karsinom gelen 38 yaşında kadın hasta adjuvan radyoterapi için kliniğimize başvurdu.

Klinik öyküsünde hastanın 1.5 y1l önce kolay yorulma ve nefes darlığı yakınması ile sağlık kuruluşuna başvurduğu ancak psikolojik nedenler üzerinde durularak herhangi bir tedavi önerilmediği, sonrasında yakınmaları geçmemesi üzerine gittiği farklı bir sağlık kuruluşunda ise astıma yönelik bronkodilatatör tedavisi başlandığı anlaşılmıştır. Bronkodilatatör kullanan hastanın yakınmalarında artış olması ve hırıltılı solunum eklenmesi üzerine

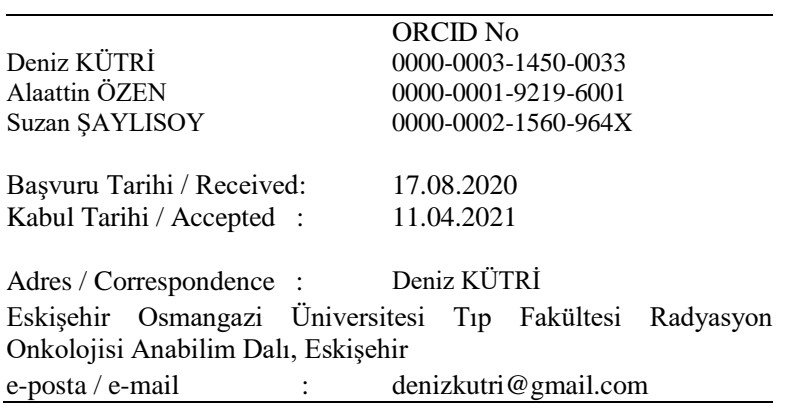

\begin{abstract}
Adenoid Cystic Carcinoma is an extremely rare disease with an incidence of $0.1-0.26$ per 100000 . It is the second most common primary malignancy of the trachea. Surgical resection is the main treatment method. However, radiotherapy treatment is recommended in patients who cannot be operated on or in the presence of postoperative microscopic/macroscopic residue. We aimed to present this rare case with a thirty-eight year old woman to whom we applied a curative radiotherapy due to the rarity of the tumor and a positive surgical margin.
\end{abstract}

Keywords: Adenoid Cystic Carcinoma, Radiotherapy, Trachea
Göğüs Hastalıkları tarafından yapılan Solunum Fonksiyon Testi (SFT) orta derecede sabit obstrüksiyon ile uyumlu olarak rapor edilmiş (FEV1 $\% 50$, FEV1/FVC \%56). Çekilen kontrol IV kontrastlı Bilgisayarlı Toraks Tomografisinde trakea yerleşimli lobüle konturlu yumuşak doku dansitesinde büyük kitle tespit edilmiştir (Resim 1A, 1B, 1C). Tiroit Ultrasonografi (USG) ve Tiroit Fonksiyon Testlerinde (TFT) herhangi bir anormallik saptanmamıştır. Trakeal kitle eksizyonu + tiroid sağ lob rezeksiyonu operasyonu uygulanan ve patoloji sonucu adenoid kistik karsinom gelen hastada lenfovasküler invazyon (-), perinöral invazyon $(+)$, distal ve proksimal cerrahi sinir (-) iken radyal cerrahi sınırı posteriorda fokal bir alanda pozitif olarak rapor edilmiștir.

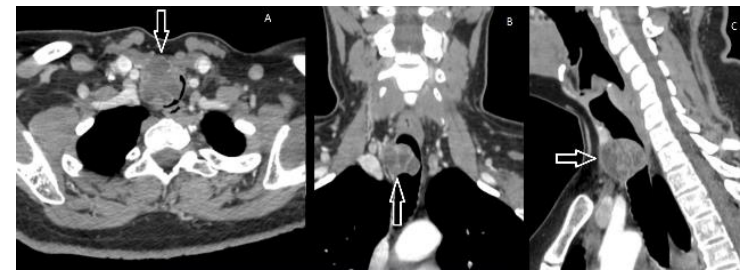

Resim 1. Tanı anında çekilen IV kontrastlı bilgisayarlı tomografi kesitleri, Aksiyel (A), Koronal (B), Sagital (C)

Tarafımıza adjuvan radyoterapi için yönlendirilen hastaya postoperatif kontrastlı bilgisayarlı tomografi çekilmiş olup trakea anterolateralinde minimal düzensizlik saptanmıştır (Resim 2). Yoğunluk Ayarlı Radyoterapi (YART) tekniği (6 MV foton ile 50-310o açılarında 2 ark) kullanılarak $60 \mathrm{~Gy} / 30$ fr eksternal radyoterapi uygulandı. Hastanın risk altındaki organ dozları; medulla spinalis için maksimum 33.1 Gy, özefagus için maksimum $63.7 \mathrm{~Gy}$, ortalama ise $15.3 \mathrm{~Gy}$ olarak hesapland1. Radyoterapi süresince grad 2 özefajit görülmüş olup konservatif yaklaşım ile kontrol altına alınd 1 ve radyoterapi tamamlanan hasta takibe alındı. Radyoterapi sonrası 3. ay kontrol bilgisayarlı 
tomografi ile değerlendirilen hastada nüks saptanmadi. Radyoterapi sahasında toksisite gözlemlenmedi.

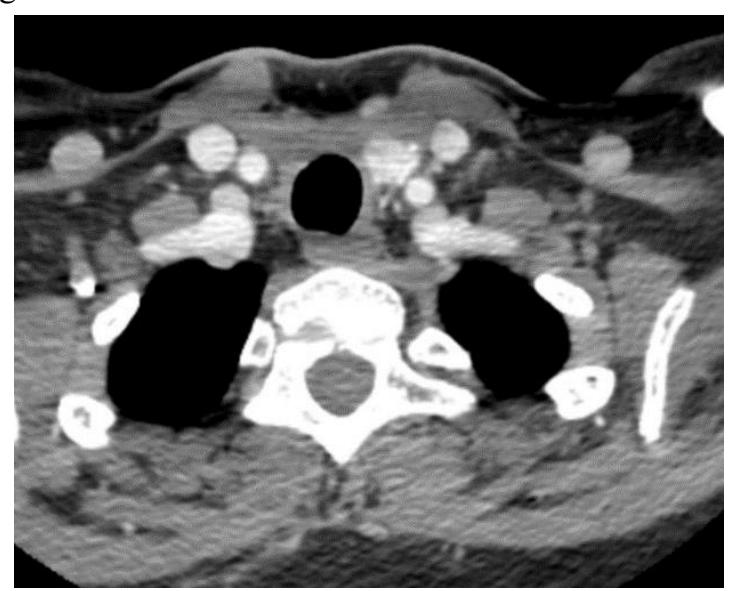

Resim 2. Postoperatif IV kontrastlı bilgisayarlı tomografi

\section{Tartışma}

Primer olarak trakea yerleşimli kanser görülme insidans1 100000'de 0.1-0.26 iken trakeal tümörler tüm malignitelerin \%0.1-0.4'ünü oluşturmaktadır. Primer trakeal tümörlerde en sik görülen patoloji skuamoz hücreli karsinom (SCC) olup bunu adenoid kistik karsinom takip etmektedir. Yetişkinlerde trakea yerleşimli primer tümörler oldukça nadir görülürken trakeal kitlelerin \%80-90'1 malign özelliktedir. Literatür incelendiğinde az sayıda hastayı içeren seriler mevcut olup trakea yerleşimli kitlesi olan 352 hastayı içeren seride hastaların \%51'inde SCC, \%31'inde adenoid kistik karsinom rapor edilmiş olup bunları daha az oranda adenokarsinom, anaplastik karsinom, küçük hücreli karsinom, lenfoma, kondrosarkom, mukoepidermoid karsinom ve karsinoid tümör izlemektedir (1-5) .

Adenoid kistik karsinom esas olarak tükürük bezlerinden ve özellikle de parotis bezinden gelişen malign bir tümördür. Baş ve boyun tümörlerinin \%10'unu adenoid kistik karsinom oluşturmakta olup primer olarak trakeadan köken alan adenoid kistik karsinom oldukça nadir görülmektedir. Histolojik olarak kribriform, tubuler ve solid formları bulunan adenoid kistik karsinom trakeanın submukozal glandlarından köken alır. Genellikle trakeanın 1/3 distal kısmından gelişirken nadiren proksimal trakea ve larenks de etkilenebilir (6). Hastamızda kitlenin proksimal trakea yerleşimli olması sunulmaya değer olduğunu desteklemektedir.

Skuamoz hücreli karsinomun aksine adenoid kistik karsinom tanılı hastalarda sigara ile ilişki gösterilememiştir. Literatürde kauçuk dumanına maruziyeti olan adenoid kistik karsinom tanılı hastalar bildirilmiş olmasına karşın henüz hangi karsinojen maddenin net olarak katkısının olduğu bilinmemekte olup kauçuk dumanının maligniteye neden olma potansiyeli bulunmaktadır. Nitröz bileşiklerin kansere neden olabileceği laboratuvar ortamında fareler üzerinde gösterilmiştir ve kauçuk dumanının da nitröz bileşikler içerdiği bilinmektedir. Kauçuk endüstrisinde çalışanlarda tükürük bezi kanseri insidansının daha yüksek olması bu şekilde açıklanmaya çalışılmış ve kauçuk dumanının bazı komponentlerinin mutajenik potansiyeli araştırılmıştır (2,7-10). Hastamızın bu tarz bir mesleki maruziyeti bulunmamaktadir.

Trakea yerleşimli adenoid kistik karsinom daha çok yaşamın 4. ve 5. dekatlarında gözlenirken her iki cinsiyet arasında istatistiksel anlamlı bir farklılık bulunmamaktadır. Hastalığın seyrine bakıldığında düşük malignite potansiyeli mevcuttur. Ancak uzun dönemde düşük oranda da olsa lokal ve uzak yinelemeler görülebilmektedir. Direk olarak submukozal ya da perinöral invazyon yoluyla lokal yayılım görülebilmekte ve uzak yayılım hematojen yolla olmaktadır. Hastaların yalnızca \%10'unda bölgesel lenf nodu ya da uzak metastaz görülürken en s1k uzak metastaz akciğerlerde görülmektedir. Tedaviden yıllar sonra bile metastaz gelişimi bildirilmiştir (11-13).

Tanı anında hava yolunda konsantrik olarak daralmaya neden olan infiltratif ya da daha az oranda sesil nodüller mevcuttur. Siklıkla stridor ve hışıltı gibi üst hava yollarında daralmaya bağlı bulgu ve semptomlar mevcut olup mukozal irritasyon ve/veya ülserasyona bağlı olarak hemoptizi ve/veya öksürük yakınmaları görülebilir. Trakea lümeni fonksiyonel olarak büyük bir rezerve sahip olduğu için lümen çapında \%50-75'lik bir daralma oluşana kadar herhangi bir yakınma olmayabilir. $\mathrm{Bu}$ solunum semptomları üst solunum yolu enfeksiyonu (ÜSYE) ya da kronik obstrüktif akciğer hastalığı (KOAH) gibi hastalıklarda da görülebildiği için tanıda gecikmeler oluşabilmektedir. Ayrıca daha ileri vakalarda özefagus invazyonuna bağlı olarak yutma güçlüğü de görülebilmektedir (7,14-16). Hastamızda nefes darlı̆̆ 1 ve kolay yorulma yakınmaları üzerine başta psikolojik faktörler üzerinde durulup öncelikle herhangi bir tedavi verilmemiş sonrasında bronkodilatatör tedavisi ile yakınmalarının geçmemesi üzerine SFT yapılarak üst solunum yolunu etkilen patolojilerden şüphelenilmiş ve görüntüleme ile trakeal kitle tespit edilmiştir.

Trakea yerleşimli adenoid kistik karsinom tanılı hastalar iyi prognoza sahip olup trakeal SCC'nin aksine uzun sağkalım süreleri bildirilmiştir. Ekstratrakeal uzanım varlığının sağkalım süresinde istatistiksel anlamlı kötüleşmeye neden olduğu bilinmektedir (5 yıllık genel sağkalım \%50 vs \%18) (17-18).

Postero-anterior (PA) ve lateral göğ̈̈s radyografisi, trakea ve merkezi hava yollarının ilk değerlendirmesi için kullanılan geleneksel çalışmalar olup elde edilen bulgular her zaman belirgin olmadığı için kesitsel görüntülemeler ile daha ileri değerlendirme gereklidir. Endoskopik değerlendirme, biyopsi ve bilgisayarlı tomografi tanı koymada kullanılmakta olup bilgisayarlı tomografi 
intraluminal ve ekstratrakeal uzanımları, kitlenin komşu yapılarla olan ilişkisini değerlendirmek için önerilmektedir. Trakeobronşiyal lezyonları değerlendirmek için bilgisayarlı tomografi en iyi non-invazif görüntüleme yöntemdir. Aksiyal görüntülere ek olarak üç boyutlu rekonstrüksiyon yapılarak elde edilen görüntüler trakeobronşiyal ağacı değerlendirmede oldukça faydalıdır. Manyetik rezonansın bilgisayarlı tomografiye kıyasla özel bir avantajı bulunmamaktadır. Endoluminal ultrason ekstratrakeal yerleşimli tümörün oluşturduğu bası ve infiltrasyonun tespitinde ve primer kitlenin submukozal uzanımının değerlendirilmesinde kullanılmakta olup rezeksiyon sonrası cerrahi sinır pozitifliğini azaltabilmektedir $(1,19,20)$.

Trakea yerleşimli adenoid kistik karsinom tanılı hastalarda tek başına cerrahi, tek başına radyoterapi ya da her iki tedavi birlikte kombine olarak uygulanabilmektedir. Cerrahi rezeksiyon olarak larenjektomi ile birlikte üst trakea rezeksiyonu, parsiyel trakea rezeksiyonu, endoskopik kitle eksizyonu ve lazer eksizyon gibi farklı prosedürler literatürde tanımlanmıştır. Trakea uzunluğunun \%50-60'ından fazlasinın tutulu olması, karina invazyonu ve mediastinal yapılara uzanım varlığ cerrahiden uzaklaştırmakta olup elektif lenf nodu diseksiyonu rutinde önerilmemektedir (21-23). Postoperatif değerlendirmede mikroskobik ya da makroskobik hastalık varlığı, medikal nedenlerle inoperabl olarak değerlendirilen hastalar radyoterapi tercih edilmektedir. Ayrica endotrakeal brakiterapi ile eksternal radyoterapi sonrası doz artırımı (boost) yapılarak lokal kontrolde iyileşme sağlanabilir $(1,24,25)$. İnkomplet rezeksiyon varlığında nüks gelişiminin daha yüksek olduğu bildirilmiştir. Tümörün çapı ve derinliği, lenf nodu tutulumu ile sağkalım arasında net ilişki istatistiksel olarak gösterilememiştir. Komplet rezeksiyon uygulanan hastalarda sağkalımın istatistiksel anlamlı olarak daha iyi olduğu bildirilmiştir $(26,27)$. Ancak Maziak ve arkadaşları tarafindan komplet ve inkomplet rezeksiyon uygulanan hastalar arasında sağkalım açısından anlamlı farklılık saptanmadığı rapor edilmiştir (28).

Sonuç olarak, trakea yerleşimli adenoid kistik karsinom oldukça nadir görülen bir tümör olup ÜSYE ve KOAH gibi farklı hastalıklarla olan semptom benzerliği nedeni ile erken tanısı her zaman mümkün olamamaktadır. $\mathrm{Bu}$ nedenle tedavideki gecikmeler cerrahiyi güçleştirmekte ya da cerrahi sınır pozitifliği gibi inkomplet cerrahi nedeni ile adjuvan radyoterapi uygulanabilmektedir.

Hasta Onamı: Hasta onamı 13.08.2020 tarihinde alınmıştır.

\section{Kaynaklar}

1. Macchiarini P. Primary tracheal tumours. Lancet Oncol. 2006; 7:83-91.
2. Bhattacharyya N. Contemporary staging and prognosis for primary tracheal malignancies: a population-based analysis. Otolaryngol Head Neck Surg. 2004;131:639-42.

3. Grillo HC. Surgery of the Trachea and Bronchi. Pmph USA Ltd., Hamilton, Ontario, 2004.

4. Shadmehr MB, Farzanegan R, Graili P, et al. Primary major airway tumors; management and results. Eur J Cardiothorac Surg. 2011;39:749-54.

5. Thotathil ZS, Agarwal JP, Shrivastava SK, Dinshaw KA. Primary malignant tumors of the trachea - the Tata Memorial Hospital experience. Med Princ Pract. 2004;13(2):69-73.

6. Calzada AP, Miller M, Lai CK, et al. Adenoid cystic carcinoma of the airway: a 30-year review at one institution. Am J Otolaryngol. 2012;33:226-31.

7. Li W, Hua W, Yan FG, Shen HH, Xu H. Adenoid cystic carcinoma of trachea: a case report and review of literature. Chin Med J (Engl). 2012;125(12):2238-9.

8. Kim D, Hwang Y, Choi S, et al. A case of tracheal adenoid cystic carcinoma in a worker exposed to rubber fumes. Ann Occup Environm Med. 2013;25:22.

9. Wingren G, Axelson O. Cancer incidence and mortality in a Swedish rubber tire manufacturing plant. Am J Ind Med. 2007;50(12):901-9.

10. Vermeulen R, Bos RP, de Hartog J, et al. Mutagenic profile of rubber dust and fume exposure in two rubber tire companies. Mutat Res. 2000;468(2):165-71.

11. Ahn Y, Chang H, Lim YS, et al. Primary tracheal tumors: review of 37 cases. J Thorac Oncol. 2009;4:635-8.

12. Haresh KP, Prabhakar R, Rath GK, et al. Adenoid cystic carcinoma of the trachea treated with PET-CT based intensity modulated radiotherapy. J Thorac Oncol. 2008;3:793-5.

13. Grillo HC, Mathisen DJ. Primary tracheal tumors: treatment and results. Ann Thorac Surg. 1990;49:69-77.

14. Qi D, Feng L, Li J, Liu B, Zhang Q. Primary adenoid cystic carcinoma of the trachea with thyroid invasion: a case report and literature review. Onco Targets Ther. 2016;9:6291-6.

15. Sarkar M, Madabhavi I, Niranjan N, Dogra M. Auscultation of the respiratory system. Ann Thorac Med. 2015;10(3):158-68.

16. Lewis S, Earley M, Rosenfeld R, Silverman J. Systematic review for surgical treatment of adult and adolescent laryngotracheal stenosis. Laryngoscope. 2017;127(1):191-8.

17. Naim A, Hajjij A, Abbad F, Rami A, Essaadi M. Rare location of head and neck adenoid cystic carcinoma. Pan Afr Med J. 2019;34:33.

18. Desai HM, Thakare R, Amonkar GP, Karkhanis V, Joshi JM. Adenoid cystic carcinoma of the trachea. Indian $\mathrm{J}$ Pathol Microbiol. 2015;58(4):516-8.

19. Kwak SH, Lee KS, Chung MJ, et al. Cystic carcinoma of the airways: helical CT and histopathologic correlation. AJR Am J Roentgenol. 2004;183:277-81.

20. Compeau CG, Keshavjee S. Management of tracheal neoplasms. Oncologist. 1996;1:347-53.

21. Azar T, Abdulkarim FW, Tucker HM. Adenoid cystic carcinoma of trachea. Laryngoscope. 1998;108:1297-300

22. Gilbert RW, Keshavjee S. Tumors of the cervical trachea. In: Myers NJ, Hanna HYE, Myers NE (eds) Cancer of the Head and Neck. Wolters Kluver Livingstone, Alphen aan den Rijn, The Netherlands, pp 500-22,1981.

23. Varela P, Pio L, Brandigi E, et al. Tracheal and bronchial tumors. J Thorac Dis. 2016;8(12):3781-6.

24. Muller A, Stockamp B, Schnabel T. Successful primary radiation therapy of adenoid cystic carcinoma of lung. Oncology. 2000;58:15-7.

25. Haddad RI, Posner MR, Busse PM, et al. Chemoradiotherapy for adenoid cystic carcinoma: preliminary results of an organ sparing approach. Am J Clin Oncol. 2006;29(2):153-7

26. Regnard JF, Fourquier P, Levasseur P. Results and prognostic factors in resections of primary tracheal tumors: a multicenter retrospective study. The French society of cardiovascular surgery. J Thorac Cardiovasc Surg. 1996;111:808-13.

27. Gaissert HA, Grillo HC, Shadmehr MB, et al. Long-term survival after resection of primary adenoid cystic and squamous cell carcinoma of the trachea and carina. Ann Thorac Surg. 2004;78;1896-7.

28. Maziak DE, Todd TR, Keshavjee SH, et al. Adenoid cystic carcinoma of the airway: thirty-two-year experience. J Thorac Cardiovasc Surg. 1996;112:1522-31 